\title{
Expression of miR-204 in pediatric retinoblastoma and its effects on proliferation and apoptosis of cancer cells
}

\author{
JIAN DING $^{1}$ and XIAOYUN LU ${ }^{2}$ \\ ${ }^{1}$ Medical Administration Division and ${ }^{2}$ Department of Oncology, The First Affiliated Hospital of \\ Hunan Normal University (People's Hospital of Hunan Province), Changsha, Hunan 410005, P.R. China
}

Received May 31, 2018; Accepted September 11, 2018

DOI: $10.3892 / \mathrm{ol} .2018 .9519$

\begin{abstract}
Expression, clinical significance and molecular mechanism of miR-204 in human retinoblastoma (RB) and para-carcinoma tissues were investigated. A total of 110 cases of RB tissues preserved after ophthalmectomy in the First Affiliated Hospital of Hunan Normal University (People's Hospital of Hunan Province) from April 2013 to June 2017 were collected along with 100 cases of para-carcinoma normal tissues. The expression of miR-204 in RB tissues was detected via reverse transcription-quantitative polymerase chain reaction (RT-qPCR), and its associations with clinicopathological features were analyzed. Y79 cells were transfected with miR-204 mimics. A total of $80 \mathrm{pmol} / 1 \mathrm{miR}-204$ mimics and $10 \mu$ l Lipofectamine 2000 were added into the experimental group. Cell proliferation was detected via methyl thiazolyl tetrazolium (MTT) assay at 24, 48, 72 and $96 \mathrm{~h}$, apoptosis was detected via flow cytometry at $48 \mathrm{~h}$ after transfection, and the relative expression levels of B-cell lymphoma 2 (Bcl-2) messenger RNA (mRNA) and Sirt1 mRNA were detected via RT-qPCR. The results of MTT assay revealed that the measured value of the optical density (OD) in the experimental group at $48 \mathrm{~h}$ was obviously lower than that in the negative control group $(\mathrm{p}<0.001)$. The proportion of apoptotic cells in the experimental group was remarkably higher than that in the negative control group $(\mathrm{p}<0.001)$. Compared with those in the negative control group, the relative expression levels of Bcl-2 and Sirt1 mRNAs in the experimental group were significantly decreased $(\mathrm{p}<0.001)$. miR-204 may be involved in the occurrence and development of RB, which is significantly associated with clinical tissue differentiation, neural infiltration and lymph node metastasis in patients. miR-204 may inhibit proliferation and promote apoptosis of RB cells through downregulating the expression of Bcl-2 and Sirt1 in
\end{abstract}

Correspondence to: Dr Xiaoyun Lu, Department of Oncology, The First Affiliated Hospital of Hunan Normal University (People's Hospital of Hunan Province), 61 Liberation West Road, Changsha, Hunan 410005, P.R. China

E-mail: xg72fh@163.com

Key words: miR-204, pediatric retinoblastoma, proliferation, apoptosis
RB. Therefore, miR-204 may become a new biological index for early diagnosis, prognosis evaluation and biotherapy of RB.

\section{Introduction}

Retinoblastoma (RB) is a primary malignant tumor in children's eyes, which frequently occurs in the retinal nuclear layer and has a familial genetic tendency $(1,2)$. RB mostly occurs in both eyes accompanied by multiple lesions, and intracranial and systemic metastasis occurs easily if the tumor grows and breaks through the eyeball, seriously threatening the life of child patients (3). Early and effective treatment can make child patients retain partial visual function and obtain longer survival time, while the optimal opportunity for treatment will be delayed if there are no timely diagnosis and treatment leading to an extremely poor prognosis of child patients. Intracranial invasion and metastasis of tumors often occur in advanced child patients after treatment, causing great harm $(4,5)$. Therefore, searching the molecular biological markers for the early diagnosis of RB, investigating the molecular signaling regulation mechanism in the occurrence and development of RB and finding the therapeutic targets for inhibiting the occurrence and development of RB are of great significance in improving the early diagnosis and treatment of $\mathrm{RB}$ and the prognosis of the patients.

Micro-ribonucleic acid (miRNA) is a newly-discovered highly-conserved endogenous non-coding hairpin nucleotide transcript, $\sim 19-25$ bases in length, which widely exists in eukaryotic cells and is generated by the endogenous pre-miRNA via Dicer cleavage, with 18-25 nucleotides in size $(6,7)$. miRNA plays different roles in different physiological processes, including developmental regulation, nervous system development, cell proliferation and apoptosis. Moreover, miRNA widely exists in tissues and cells, and is involved in a series of vital activities, such as individual development, cell proliferation, apoptosis and differentiation, which is closely related to the occurrence and development of a variety of malignant tumors, so it can serve as a therapeutic target for various malignant tumors $(8,9)$. Currently, a large number of studies have found that some specific miRNAs are abnormally expressed in RB and have close associations with the occurrence and development of RB (10). miR-204 has been studied in a variety of malignant tumors, including breast, gastric, prostate and endometrial cancer, and its expression is 
low in these tumors. miR-204 can bind to target genes to be involved in the pathway of tumor cells, affecting the growth of tumor cells and playing a role as cancer suppressor gene in a variety of malignant tumors $(11,12)$. Y79 cells are established via the primary culture of tumors resected from the right eye of RB patients with a strong RB maternal familial heredity, whose ultrastructures, such as nuclear membrane infolding, trilamellar membrane structure, coated vesicle, microtubule, centriole, annulate lamellae and basal granule, are similar to those of RB (13).

Studies have demonstrated that miR-204 is expressed at low level in RB tissues (14), but its specific biological effect and mechanism in RB have not been clarified and need further studies. In this study, the miR-204 expression in RB and para-carcinoma tissues was detected, its associations with clinicopathological features of patients were analyzed, and the expression, clinical significance and biological effect on $\mathrm{RB}$ cells were explored via the in vitro experiment of transient transfection of Y79 cells with miR-204 mimics, so as to provide clinical reference bases for early diagnosis, treatment and prognosis evaluation of RB.

\section{Materials and methods}

General information. A total of 110 cases of RB tissues were collected after ophthalmectomy in the First Affiliated Hospital of Hunan Normal University (People's Hospital of Hunan Province) (Changsha, China) from April 2013 to June 2017. Another 100 cases of para-carcinoma normal tissues ( $>1 \mathrm{~cm}$ away from the tumor lesion) were collected. Among the 110 patients with RB, there were 51 males and 59 females, aged from 4 months to 11 years with an average age of $3.2 \pm 1.6$ years, 46 cases with monocular RB and 64 cases with binocular RB. The degree of tissue differentiation was judged based on the international intraocular RB classification criteria (15), and there were 21 cases of undifferentiated type and 89 cases of differentiated type. In terms of clinical stage, there were 41 cases of intraocular stage, 36 cases of glaucoma stage, and 33 cases of extended stage. Moreover, there were 69 cases with neural infiltration and 41 cases without neural infiltration. Inclusion criteria: patients who did not receive any treatment before surgery, patients whose tissue sections were diagnosed by the chief physician of the Pathology Department in the First Affiliated Hospital of Hunan Normal University (People's Hospital of Hunan Province), patients with complete clinical data. Exclusion criteria: patients with a history of mental disease and a family history of mental disease, or patients complicated with severe heart, lung, liver and renal dysfunction. Only one eye was taken from patients with binocular RB as specimen, and immediately placed in liquid nitrogen for $5 \mathrm{~h}$ and then stored at $-80^{\circ} \mathrm{C}$ for cryopreservation. This study was approved by the Ethics Committee of the First Affiliated Hospital of Hunan Normal University (People's Hospital of Hunan Province), and the patients and their families were informed and signed the informed consent.

Main instruments and reagents. RNA extraction kit (TRIzol method) and liposome (Lipofectamine 2000) for cell transfection were purchased from Invitrogen (Invitrogen: Thermo Fisher Scientific, Inc., Waltham, MA, USA). miR-204, B-cell lymphoma 2 (Bcl-2) and Sirtl reverse transcription-quantitative polymerase chain reaction (RT-qPCR) kits were purchased from Takara Bio, Inc. (Otsu, Japan). M-MLV reverse transcription kit was purchased from Applied Biosystems (Applied Biosystems: Thermo Fisher Scientific, Inc., Waltham, MA, USA). The UV-1900 double-beam UV Spectrophotometer was purchased from Yoke Instrument Co., Ltd. (Shanghai, China). The SYBR-Green qPCR Master Mix kit was purchased from Thermo Fisher Scientific, Inc. (Shanghai, China). RB Y79 and HXO-Rb44 cell lines and human retinal microvascular endothelial cell line ACBRI-181 were purchased from Shanghai Guandao Bio-engineering, Ltd. (Shanghai, China). miR-204 and its corresponding negative control plasmid were purchased from Shanghai BioLeaf Biotech Co., Ltd. (Shanghai, China). Blue methyl thiazolyl tetrazolium (MTT), dimethyl sulfoxide (DMSO) and Annexin V-FITC/PI apoptosis detection kits were from Beijing Solarbio Science \& Technology Co., Ltd. (Beijing, China). Real-time fluorescence quantitative PCR and CytoFLEX S series flow cytometry were from Beckman Coulter, Inc. (Brea, CA, USA). The primers used in real-time fluorescence quantitative PCR for miR-204, Bcl-2 messenger RNA (mRNA), Sirt1 mRNA and $\beta$-actin were synthesized by Invitrogen: Thermo Fisher Scientific, Inc. The required primer sequences are shown in Table I.

Cell culture and transfection. Cell culture: the human RB Y79, HXO-Rb44 cell lines and human retinal microvascular endothelial cell line ACBRI-181 were cultured in high-glucose Dulbecco's modified Eagle's medium (DMEM) supplemented with $15 \%$ fetal bovine serum and $1 \%$ penicillin/streptomycin in an incubator under $5 \% \mathrm{CO}_{2}$ at $37^{\circ} \mathrm{C}$, followed by culture at constant temperature and saturated humidity. Cells were stabilized for 2-3 generations, and the medium was replaced in time. Cell transfection: the cell transfection was performed with reference to the instructions of Lipofectamine 2000 for cell transfection. The cells in the logarithmic growth phase were inoculated into a 6 -well plate at a concentration of $1 \times 10^{5}$ cells/well, and the transfection was performed when $25-50 \%$ cells were fused on the next day. In the experimental group, $80 \mathrm{pmol} / 1 \mathrm{miR}-204$ mimics and $10 \mu \mathrm{l}$ Lipofectamine 2000 were added into the well plate. In the control group, $80 \mathrm{pmol} / \mathrm{l}$ negative control and $10 \mu \mathrm{l}$ Lipofectamine 2000 were added into each well. The plate in both two groups was placed in a constant-temperature incubator under $5 \% \mathrm{CO}_{2}$ at $37^{\circ} \mathrm{C}$ for incubation.

$R T$ - $q P C R$ detection. The total RNA was extracted from tissues and cells using the RNA extraction kit. The absorption value of RNA extracted was determined by UV-1900 double-beam UV Spectrophotometer and the integrity of total RNA was determined by $1 \%$ agarose gel electrophoresis. Total RNA $(1 \mu \mathrm{l})$ was taken and reversely transcribed into cDNA according to the instructions of the M-MLV reverse transcription kit. The reaction system was as follows: $10 \mu \mathrm{l}$ RNA and $10 \mu \mathrm{l}$ oligo(dT) were evenly mixed in a thin-walled tube, followed by heating at $65^{\circ} \mathrm{C}$ for $30 \mathrm{~min}, 10 \mu \mathrm{l}$ 2X SYBR-Green qPCR Master Mix solution were added and mixed evenly, and then RNase-free water was added until the total volume was $20 \mu \mathrm{l}$, followed by reaction at $37^{\circ} \mathrm{C}$ for $2.5 \mathrm{~h}$ and heating at $65^{\circ} \mathrm{C}$ for $30 \mathrm{~min}$. After cooling for $1 \mathrm{~min}, 20 \mu \mathrm{l} \mathrm{cDNA}$ were diluted to $100 \mu \mathrm{l}$ with deionized water and stored at $-80^{\circ} \mathrm{C}$ for use. cDNA was used for the RT-qPCR 
Table I. Primer sequences for the reference genes miR-204, Bcl-2 mRNA, Sirt1 mRNA and $\beta$-actin.

\begin{tabular}{lll}
\hline Gene & \multicolumn{1}{c}{ Forward primer sequence } & \multicolumn{1}{c}{ Reverse primer sequence } \\
\hline miR-204 & 5'-AACCUGAUCCCGUCUGAGAUUG-3' & 5'-CCGGAUCAAGAUUAGUUCGGUU-3' \\
Bcl-2 & 5'-CCTTTGTGTAACTGTACGGCC-3' & 5'-CTTTGGCAGTAAATAGCTGATTCGAC-3' \\
Sirt1 & 5'-CAAAGGAGCAGATTAGTAGGCG-3' & 5'-CTCTGGCATGTCCCACTATCAC-3' \\
$\beta$-actin & 5'-ATCATGTTTGAGACCTTCAACA-3' & 5'-CATCTCTTGCTCGAAGTCCA-3' \\
\hline
\end{tabular}

Bcl-2, B-cell lymphoma 2; mRNA, messenger RNA.

detection of miR-204, Bcl-2 and Sirt1, with $\beta$-actin as an internal reference. PCR conditions were as follows: pre-denaturation at $94^{\circ} \mathrm{C}$ for $3 \mathrm{~min}, 35$ cycles, denaturation at $95^{\circ} \mathrm{C}$ for $10 \mathrm{sec}$, annealing at $65^{\circ} \mathrm{C}$ for $8 \mathrm{sec}$, extension at $72^{\circ} \mathrm{C}$ for $1 \mathrm{~min}$ and then extension again at $72^{\circ} \mathrm{C}$ for $10 \mathrm{~min}$. After the reaction, the $\mathrm{Cq}$ value of each reaction tube was obtained. The relative expression levels of miR-204, Bcl-2 mRNA and Sirt1 mRNA were analyzed via $2^{-\Delta \mathrm{Cq}}$ for relative gene quantification (16).

Cell proliferation and apoptosis detection. Cell proliferation was detected by the MTT method. The cells in the logarithmic growth phase were prepared into the cell suspension $\left(1 \times 10^{5}\right)$ and inoculated into a 96-well plate at a density of $3 \times 10^{3}$ cells/well. The cell viability was detected by MTT once every 24 h, 4 times until 96 h. For the detection, $20 \mu 1$ MTT solution $(5 \mathrm{mg} / \mathrm{ml})$ were added into each well. After cells being incubated in the incubator for $4 \mathrm{~h}$, the culture medium was discarded and $150 \mu \mathrm{l}$ DMSO were added into each well. The crystals were dissolved via vibration for $10 \mathrm{~min}$ at room temperature. The optical density (OD) at the wavelength of $490 \mathrm{~nm}$ in each well was repeatedly detected 3 times using a microplate reader. Apoptosis was detected by flow cytometry. The cells transfected for $48 \mathrm{~h}$ were collected and digested by trypsin, and then washed with $0.01 \mathrm{~mol} / 1$ cold phosphate-buffered saline (PBS). The supernatant was discarded after centrifugation at $111.8 \times \mathrm{g}$ under the temperature of $25^{\circ} \mathrm{C}$. The cells were re-suspended with $100 \mu \mathrm{l} 1 \mathrm{X}$ binding buffer, and then transferred to the flow detection tube. A total of $5 \mu 1$ 7-AAD and $5 \mu \mathrm{l}$ PE Annexin $\mathrm{V}$ were added into each tube, followed by reaction for $15 \mathrm{~min}$ at room temperature without light. Then $400 \mu \mathrm{l} 1 \mathrm{X}$ binding buffer were added. Flow cytometry was completed within $1 \mathrm{~h}$, and each specimen was repeatedly detected 3 times.

Statistical methods. The SPSS 19.0 software (IBM Corp., Beijing, China) was used for statistical analysis. The measurement data were expressed as mean \pm standard deviation (SD) and compared among groups by t-test. The mean values among multiple groups were compared via the one-way analysis of variance, and the Dunnett's test was the post hoc test used. $\mathrm{P}<0.05$ was considered to indicate a statistically significant difference.

\section{Results}

Expression of miR-204 in RB and para-carcinoma normal tissues. The results of RT-qPCR showed that the relative expression of miR-204 in RB tissues was 3.164 \pm 0.611 , and in
Table II. Association of the relative expression levels of miR-204 with clinicopathological parameters of RB patients $(\overline{\mathrm{X}} \pm \mathrm{s})$.

\begin{tabular}{|c|c|c|c|c|}
\hline Item & $\mathrm{n}$ & miR-204 & $\mathrm{t}$ & P-value \\
\hline Age (years) & & & 1.717 & 0.088 \\
\hline$<4$ & 67 & $3.211 \pm 0.542$ & & \\
\hline$\geq 4$ & 43 & $3.016 \pm 0.638$ & & \\
\hline Sex & & & 0.338 & 0.735 \\
\hline Male & 51 & $3.134 \pm 0.673$ & & \\
\hline Female & 59 & $3.173 \pm 0.535$ & & \\
\hline Affected eye & & & 1.929 & 0.056 \\
\hline Single eye & 46 & $2.984 \pm 0.531$ & & \\
\hline Both eyes & 64 & $3.204 \pm 0.629$ & & \\
\hline $\begin{array}{l}\text { Degree of tissue } \\
\text { differentiation }\end{array}$ & & & 5.277 & $<0.001$ \\
\hline Undifferentiated type & 21 & $3.495 \pm 0.871$ & & \\
\hline Differentiated type & 89 & $2.772 \pm 0.468$ & & \\
\hline Clinical stage & & & 1.358 & 0.261 \\
\hline Intraocular stage & 41 & $3.241 \pm 0.731$ & & \\
\hline Glaucoma & 36 & $3.161 \pm 0.467$ & & \\
\hline Extended stage & 33 & $3.011 \pm 0.547$ & & \\
\hline Neural infiltration & & & 9.845 & $<0.001$ \\
\hline Yes & 69 & $2.614 \pm 0.337$ & & \\
\hline No & 41 & $3.841 \pm 0.941$ & & \\
\hline Lymph node metastasis & & & 9.462 & $<0.001$ \\
\hline Yes & 43 & $2.547 \pm 0.271$ & & \\
\hline No & 67 & $3.816 \pm 0.851$ & & \\
\hline
\end{tabular}

$\mathrm{RB}$, retinoblastoma.

para-carcinoma normal tissues was $9.164 \pm 2.016$. The relative expression of miR-204 in RB tissues was significantly lower than that in para-carcinoma normal tissues $(\mathrm{p}<0.001)$ (Fig. 1).

Association of the relative expression of $m i R-204$ in $R B$ tissues with clinicopathological parameters of patients. The relative expression of miR-204 in RB tissues had no significant association with age, sex, affected eyes and clinical stage ( $p>0.05)$, but had significant association with the degree of tissue differentiation, neural infiltration and lymph node metastasis $(\mathrm{p}<0.001)$ (Table II). 


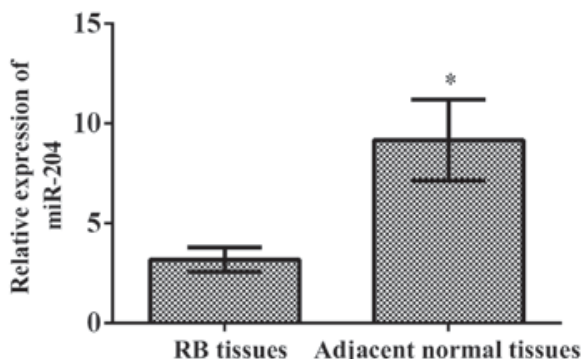

Figure 1. Expression of miR-204 in RB and para-carcinoma normal tissues. The results of RT-qPCR showed that the relative expression of miR-204 in $\mathrm{RB}$ tissues is significantly lower than that in para-carcinoma normal tissues $(\mathrm{p}<0.001)$. $\mathrm{P}<0.001$ vs. RB tissues. RB, retinoblastoma; RT-qPCR, reverse transcription-quantitative polymerase chain reaction.

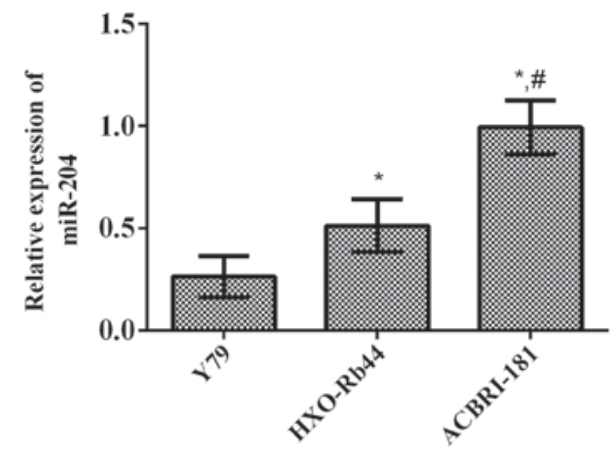

Figure 2. Expression of miR-204 in human RB cells. The results of RT-qPCR revealed that the relative expression levels of miR-204 in human RB cell lines (Y79 and HXO-Rb44) are obviously lower than that in the human retinal microvascular endothelial cell line (ACBRI-181) ( $\mathrm{p}<0.001) .{ }^{*} \mathrm{P}<0.01$ vs. Y79, ${ }^{\#} \mathrm{p}<0.01$ vs. HXO-Rb44. RB, retinoblastoma; RT-qPCR, reverse transcription-quantitative polymerase chain reaction.

Expression of miR-204 in human $R B$ cells. The results of RT-qPCR revealed that the relative expression levels of miR-204 in human RB cell lines (Y79 and HXO-Rb44) and human retinal microvascular endothelial cell line (ACBRI-181) were 0.264 $\pm 0.101,0.513 \pm 0.129$ and $0.994 \pm 0.131$, respectively. It can be seen that the relative expression levels of miR-204 in human RB cell lines (Y79 and HXO-Rb44) were significantly lower than that in human retinal microvascular endothelial cell line (ACBRI-181) $(\mathrm{p}<0.01$ and $\mathrm{p}<0.001$, respectively) (Fig. 2).

Transfection of human RB Y79 cells with miR-204. To further study the effect of miR-204 on the biological behavior of RB, Y79 cells were transfected with miR-204. The results of RT-qPCR showed that the relative expression level of miR-204 in the experimental group $(3.386 \pm 0.863)$ was significantly higher than that in the negative control group $(0.244 \pm 0.107)$ after transfection ( $\mathrm{p}<0.001)$ (Fig. 3).

Effect of miR-204 overexpression on proliferation capacity of human RB Y79 cells. To further study the effect of miR-204 on the proliferation capacity of human RB Y79 cells after transfection, the proliferation of Y79 cells was detected via MTT assay at 24, 48, 72 and $96 \mathrm{~h}$ after transfection with miR-204. The results showed that the measured value of OD in the experimental group was significantly lower than that in

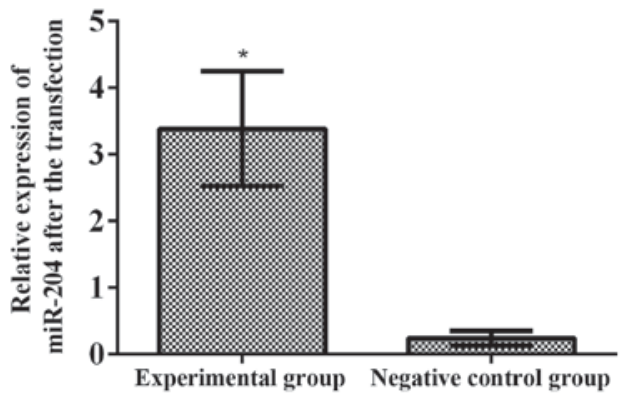

Figure 3. Transfection of human RB Y79 cells with miR-204. The results of RT-qPCR revealed that the relative expression level of miR-204 in the experimental group after transfection is significantly higher than that in the negative control group $(\mathrm{p}<0.001)$. ${ }^{*} \mathrm{P}<0.001 \mathrm{vs}$. negative control group. $\mathrm{RB}$, retinoblastoma; RT-qPCR, reverse transcription-quantitative polymerase chain reaction.

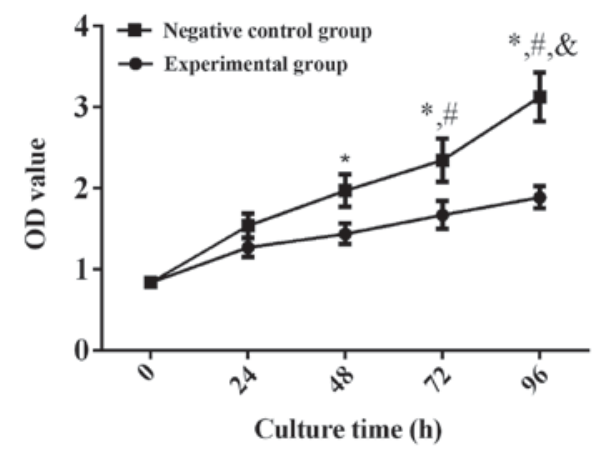

Figure 4. Effect of miR-204 overexpression on the proliferation capacity of human RB Y79 cells. The results of MTT assay showed that the measured value of OD in the experimental group at $48 \mathrm{~h}$ is obviously lower than that in the negative control group $(\mathrm{p}<0.001)$, indicating that miR-204 can significantly inhibit proliferation capacity of human RB Y79 cells. " $\mathrm{P}<0.01$ vs. $24 \mathrm{~h}$, ${ }^{\#}$ p $<0.01$ vs. 48 h, ${ }^{\&}$ p $<0.01$ vs. 72 h. RB, retinoblastoma; MTT, methyl thiazolyl tetrazolium; OD, optical density.

the negative control group at $48 \mathrm{~h}(\mathrm{p}<0.001)$, indicating that miR-204 can significantly inhibit the proliferation capacity of human RB Y79 cells (Fig. 4).

Effect of miR-204 overexpression on apoptosis of human $R B$ Y79 cells. To further study the effect of miR-204 on the apoptosis of human RB Y79 cells after transfection, the proportion of apoptotic human RB Y79 cells was detected via flow cytometry. The results revealed that the proportion of apoptotic cells in the experimental group $(23.16 \pm 4.58 \%)$ was obviously higher than that in the negative control group $(4.77 \pm 4.58 \%)$ after transfection with miR-204 (p<0.001) (Fig. 5).

Effect of miR-204 overexpression on Bcl-2 and Sirtl expression levels in human RB Y79 cells. To explore the biological mechanism of miR-204 in regulating the proliferation and apoptosis of RB cells, changes in the expression of Bcl-2 mRNA and Sirt1 mRNA in human RB Y79 cells after overexpression of miR-204 were detected via RT-qPCR. The results demonstrated that compared with those in control group, the relative expression levels of Bcl-2 mRNA and Sirt1 mRNA in the experimental group obviously declined $(p<0.001)$ (Fig. 6). 


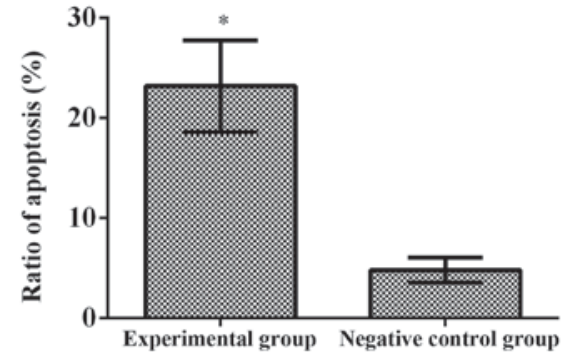

Figure 5. Effect of miR-204 overexpression on the apoptosis of human RB Y79 cells. The results of flow cytometry manifested that the proportion of apoptotic cells in the experimental group is remarkably higher than that in the negative control group after transfection with miR-204 $(\mathrm{p}<0.001)$. ${ }^{*} \mathrm{P}<0.001$ vs. negative control group. $\mathrm{RB}$, retinoblastoma.

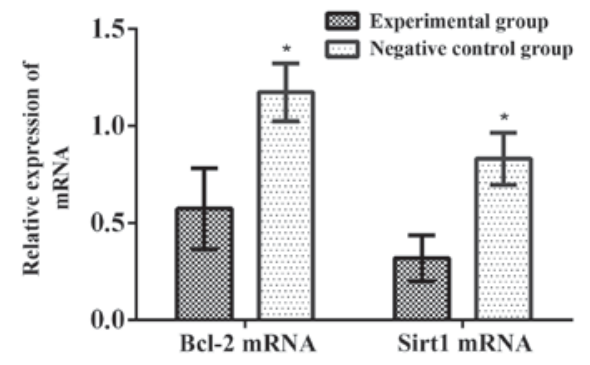

Figure 6. Effect of miR-204 overexpression on Bcl-2 and Sirt1 expression in human RB Y79 cells. The results of RT-qPCR displayed that compared with those in the negative control group, the relative expression levels of Bcl-2 and Sirt 1 mRNAs in the experimental group are significantly decreased (p<0.001). "P<0.001 vs. experimental group. Bcl-2, B-cell lymphoma 2; RB, retinoblastoma; RT-qPCR, reverse transcription-quantitative polymerase chain reaction; mRNA, messenger RNA.

\section{Discussion}

$\mathrm{RB}$ is a kind of common primary malignant tumor occurring frequently in the retina of children. The clinical treatment methods of RB are mainly ophthalmectomy, chemotherapy, radiotherapy and cryotherapy. Despite the continuous improvement of the treatment methods, the therapeutic effect on most child patients is limited, and both visual function and quality of life of the child patients are often seriously affected after treatment (17). The improvement of medical level and the gradual development of molecular biology help provide new thoughts for the gene-targeted therapy of RB. The specific mechanism of the occurrence and development of RB has not been clarified, but the proliferation and apoptosis of tumor cells is considered as one of the mechanisms of RB occurrence (18). Therefore, studying the specific pathogenic mechanism of $\mathrm{RB}$ and investigating the molecular biological markers and the therapeutic targets closely related to the occurrence and development of RB is important for the early diagnosis and molecular therapy of RB.

miRNA is a non-coding RNA molecule, $19-25$ nucleotides in length, which can be involved in molecular biological processes, such as cell proliferation, apoptosis, differentiation, metabolism and death, through regulating gene expression at the transcriptional or post-transcriptional level (19). Studies have demonstrated that miRNA plays a key role in the development process of a variety of cells, which has close association with cell differentiation, morphogenesis and tumorigenesis (20). miRNA plays a role as oncogene or cancer suppressor gene in the occurrence of various human tumors, and can serve as an effective molecular biological index for early diagnosis, treatment and prognosis evaluation of tumors (21). The results in this study manifested that the relative expression level of miR-204 in RB tissues was significantly lower than that in para-carcinoma normal tissues, and had significant associations with clinicopathological parameters (degree of tissue differentiation, neural infiltration and lymph node metastasis) of RB patients ( $\mathrm{p}<0.001)$, indicating that miR-204 may play an important role in the occurrence and development of RB. Montagnana et al (22) have shown that miR-204 inhibits proliferation and promotes apoptosis of tumor cells in endometrial and pancreatic cancer. In this study, miR-204 was transiently transfected in vitro to be overexpressed in human RB Y79 cell lines. The results of MTT assay revealed that the measured value of $\mathrm{OD}$ in the experimental group at $48 \mathrm{~h}$ was obviously lower than that in the negative control group, and the results of flow cytometry showed that the proportion of apoptotic cells in the experimental group was remarkably higher than that in the negative control group after transfection, suggesting that miR-204 can inhibit proliferation capacity and promote apoptosis of human RB Y79 cells.

$\mathrm{Bcl}-2$ protein is an important regulatory factor in the process of apoptosis, which, like most oncogenes, can inhibit apoptosis and be involved in the occurrence and development of tumors (23). Canu et al (24) have shown that in human gastric cancer cells, miR-204 can reduce the Bcl-2 gene expression, enhance the therapeutic effect of 5-fluorouracil and promote apoptosis. Sirt1 is a highly-conserved deacetylase dependent on $\mathrm{NAD}^{+}$, which can regulate cell proliferation, stress responses and DNA damage (25). According to the study of Yuan et al (26), Sirt1 is one of the downstream target genes of miR-204 in human gastric cancer cells, and miR-204 inhibits the invasion and metastasis of gastric cancer cells through downregulating the Sirt1 expression, thus exerting an antitumor effect. It was found in this study that compared with those in the negative control group, the relative expression levels of Bcl-2 and Sirt1 mRNAs in the experimental group were significantly decreased, indicating that miR-204 may inhibit proliferation and promote apoptosis of RB cells through downregulating the expression of Bcl-2 and Sirtl in RB.

In this study, the effects of miR-204 on proliferation and apoptosis of RB cells were observed, and the roles of miR-204 during these processes were also analyzed, so as to provide a theoretical basis for the gene-targeted therapy of RB. In this research, the mechanism of miR-204 in RB cells was explored preliminarily, but its pathway mechanism could not be verified in more detail, so there were certain limitations. Cells in vitro rather than in vivo were used in the present study as research objects for ethical reasons. The environment in the body is complex, so whether miR-204 has such effects on RB cells in the human body and whether it is affected by the surrounding relevant genes need further clinical research and animal experiments.

In conclusion, miR-204 may be involved in the occurrence and development of RB, which is significantly associated with clinical tissue differentiation, neural infiltration and lymph node metastasis in patients. miR-204 may inhibit proliferation 
and promote apoptosis of $\mathrm{RB}$ cells through downregulating the Bcl-2 and Sirt1 expression levels in RB. Therefore, miR-204 may become a new biological index for early diagnosis, prognosis evaluation and biotherapy of RB.

\section{Acknowledgements}

Not applicable.

\section{Funding}

No funding was received.

\section{Availability of data and materials}

The datasets used and/or analyzed during the present study are available from the corresponding author on reasonable request.

\section{Authors' contributions}

JD drafted the manuscript. JD and XL were responsible for the acquisition and interpretation of the data. JD revised it critically for important intellectual content. JD and XL were responsible for the conception and design of the study. Both authors read and approved the final manuscript.

\section{Ethics approval and consent to participate}

The study was approved by the Ethics Committee of the First Affiliated Hospital of Hunan Normal University (People's Hospital of Hunan Province) (Changsha, China). Signed informed consents were obtained from the patients or the guardians.

\section{Patient consent for publication}

Not applicable.

\section{Competing interests}

The authors declare that they have no competing interests.

\section{References}

1. Rosenberg A and Mahalingam D: Immunotherapy in pancreatic adenocarcinoma-overcoming barriers to response. J Gastrointest Oncol 9: 143-159, 2018

2. Eldehna WM, Al-Wabli RI, Almutairi MS, Keeton AB, Piazza GA, Abdel-Aziz HA and Attia MI: Synthesis and biological evaluation of certain hydrazonoindolin-2-one derivatives as new potent anti-proliferative agents. J Enzyme Inhib Med Chem 33: 867-878, 2018.

3. Garsed DW, Alsop K, Fereday S, Emmanuel C, Kennedy CJ, Etemadmoghadam D, Gao B, Gebski V, Garès V, Christie EL, et al Nadia Traficante, for the Australian Ovarian Cancer Study Group: Homologous recombination DNA repair pathway disruption and retinoblastoma protein loss are associated with exceptional survival in high-grade serous ovarian cancer. Clin Cancer Res 24 569-580, 2018

4. Qi DL and Cobrinik D: MDM2 but not MDM4 promotes retinoblastoma cell proliferation through $\mathrm{p} 53$-independent regulation of MYCN translation. Oncogene 36: 1760-1769, 2017.

5. Medina-Cleghorn D and Nomura DK: Chemical approaches to study metabolic networks. Pflugers Arch 465: 427-440, 2013.
6. Zhang WF, Xiong YW, Zhu TT, Xiong AZ, Bao HH and Cheng XS: MicroRNA let-7g inhibited hypoxia-induced proliferation of PASMCs via G0/G1 cell cycle arrest by targeting c-myc. Life Sci 170: 9-15, 2017.

7. Zhang HF, Wang YC and Han YD: MicroRNA-34a inhibits liver cancer cell growth by reprogramming glucose metabolism. Mol Med Rep 17: 4483-4489, 2018.

8. Suzuki HI, Young RA and Sharp PA: Super-enhancer-mediated RNA processing revealed by integrative microRNA network analysis. Cell 168: 1000-1014.e15, 2017.

9. Zhang X, Fan F, Huo Y and Xu X: Identifying the optimal blood pressure target for ideal health. J Transl Int Med 4: 1-6, 2016.

10. Castro-Magdonel BE, Orjuela M, Camacho J, García-Chéquer AJ, Cabrera-Muñoz L, Sadowinski-Pine S, Durán-Figueroa N, Orozco-Romero MJ, Velázquez-Wong AC, Hernández-Ángeles A, et al: miRNome landscape analysis reveals a 30 miRNA core in retinoblastoma. BMC Cancer 17: 458-470, 2017.

11. Golabchi K, Soleimani-Jelodar R, Aghadoost N, Momeni F, Moridikia A, Nahand JS, Masoudifar A, Razmjoo H and Mirzaei H: MicroRNAs in retinoblastoma: Potential diagnostic and therapeutic biomarkers. J Cell Physiol 233: 3016-3023, 2018.

12. Gao N, Wang FX, Wang G and Zhao QS: Targeting the HMGA2 oncogene by miR-498 inhibits non-small cell lung cancer biological behaviors. Eur Rev Med Pharmacol Sci 22: 1693-1699, 2018.

13. Yang G, Fu Y, Zhang L, Lu X and Li Q: miR106b regulates retinoblastoma Y79 cells through Runx3. Oncol Rep 38: 3039-3043, 2017.

14. Guo R, Shen W, Su C, Jiang S and Wang J: Relationship between the pathogenesis of glaucoma and miRNA. Ophthalmic Res 57: 194-199, 2017.

15. Scelfo C, Francis JH, Khetan V, Jenkins T, Marr B, Abramson DH, Shields CL, Pe'er J, Munier F, Berry J, et al: An international survey of classification and treatment choices for group D retinoblastoma. Int J Ophthalmol 10: 961-967, 2017

16. Cheng J, Chen Y, Zhao P, Li N, Lu J, Li J, Liu Z, Lv Y and Huang C: Dysregulation of miR-638 in hepatocellular carcinoma and its clinical significance. Oncol Lett 13: 3859-3865, 2017.

17. Liu ZP, Zhou KY, Chen LL, Xiao ZH and Chen YZ: A preliminary study of retinoblastoma-related serum tumor markers. Zhongguo Dang Dai Er Ke Za Zhi 19: 318-321, 2017 (In Chinese).

18. Guo L, Huang C and Ji QJ: Aberrant promoter hypermethylation of p16, survivin, and retinoblastoma in gastric cancer. Bratisl Lek Listy 118: 164-168, 2017.

19. Colden M, Dar AA, Saini S, Dahiya PV, Shahryari V, Yamamura S, Tanaka Y, Stein G, Dahiya R and Majid S: MicroRNA-466 inhibits tumor growth and bone metastasis in prostate cancer by direct regulation of osteogenic transcription factor RUNX2. Cell Death Dis 8: e2572, 2017.

20. Li JH, Sun SS, Fu CJ, Zhang AQ, Wang C, Xu R, Xie SY and Wang PY: Diagnostic and prognostic value of microRNA-628 for cancers. J Cancer 9: 1623-1634, 2018.

21. Adams FF, Hoffmann T, Zuber J, Heckl D, Schambach A and Schwarzer A: Pooled generation of lentiviral tetracycline-regulated microRNA embedded short hairpin RNA libraries. Hum Gene Ther Methods 29: 16-29, 2018.

22. Montagnana M, Benati M, Danese E, Giudici S, Perfranceschi M, Ruzzenenete O, Salvagno GL, Bassi A, Gelati M, Paviati E, et al: Aberrant MicroRNA expression in patients with endometrial cancer. Int J Gynecol Cancer 27: 459-466, 2017.

23. Chen C, Liu TS, Zhao SC, Yang WZ, Chen ZP and Yan Y: XIAP impairs mitochondrial function during apoptosis by regulating the Bcl-2 family in renal cell carcinoma. Exp Ther Med 15: 4587-4593, 2018

24. Canu V, Sacconi A, Lorenzon L, Biagioni F, Lo Sardo F, Diodoro MG, Muti P, Garofalo A, Strano S, D'Errico A, et al: MiR-204 down-regulation elicited perturbation of a gene target signature common to human cholangiocarcinoma and gastric cancer. Oncotarget 8: 29540-29557, 2017.

25. Wang J, Wang H, Hao Y, Yang S, Tian H, Sun B and Liu Y: A novel reaction-based fluorescent probe for the detection of cysteine in milk and water samples. Food Chem 262: 67-71, 2018.

26. Yuan X, Wang S, Liu M, Lu Z, Zhan Y, Wang W and Xu AM: Histological and pathological assessment of miR-204 and SOX4 levels in gastric cancer patients. Biomed Res Int 2017: 6894675, 2017. International (CC BY-NC-ND 4.0) License. 